\title{
LA CAPILLA MAYOR Y LA SACRISTÍA DE LA IGLESIA CONVENTUAL DE LA MERCED DE BAZA
}

\author{
JUAN MANUEL SEGURA FERRER \\ Universidad de Granada \\ CÉSAR VALERO SEGURA \\ Universidad de Granada
}

\begin{abstract}
Resumen
La capilla mayor y la sacristía de la iglesia de la Merced de Baza, obras notables de la arquitectura conventual del sudeste español, siguen la solución más habitual en las construcciones de cantería del siglo XVI en el norte del Reino de Granada, una síntesis entre lo moderno y lo antiguo, una simbiosis entre la arquitectura renacentista y los últimos coletazos del gótico. Estas edificaciones nos hablan de la importancia de la producción arquitectónica del quinientos en las altiplanicies granadinas y del destacado papel de Rodrigo de Gibaja, y otros canteros, a nivel andaluz.
\end{abstract}

\section{Palabras claves}

Siglo XVI, Baza, arquitectura, convento de la Merced, capilla mayor, sacristía, tardogótico, renacimiento, Rodrigo de Gibaja, Martín de Alzaga, Sebastián de Lizana y Jusepe Díaz.

\section{THE MAIN CHAPEL AND THE SACRISTY OF THE CONVENT CHURCH OF LA MERCED DE BAZA}

\section{Summary}

The main chapel and the sacristy of the church of La Merced de Baza, remarkable works of the conventual architecture of south-east Spain, follow the most usual solution in the stonework constructions of the XVI century in the north of the Kingdom of Granada, a synthesis between modern and ancient, a symbiosis between Renaissance architecture and the last throes of the Gothic. These buildings tell us about the importance of the architectural production of the five hundred in the granadian highlands and the prominent role of Rodrigo de Gibaja, and other stonemasons, at the Andalusian level.

\section{Keywords}

16th century, Baza, architecture, La Merced convent, chapel, sacristy, late Gothic, Renaissance, Rodrigo de Gibaja, Martín de Alzaga, Sebastián de Lizana and Jusepe Díaz. 


\section{Introducción}

Tras el terremoto de septiembre de 1531 la ciudad de Baza quedó asolada y la mayoría de sus iglesias parroquiales y conventuales en ruinas. El conjunto monacal de la Merced debió resultar muy afectado, no habiéndose localizado hasta el momento una relación pormenorizada sobre los daños sufridos. Dicho cenobio se había levantado sobre la ermita de nuestra señora de la Piedad, fundada por Luis de Acuña. Con posterioridad Melchor de Luna y Constanza de Lugo se convirtieron en los patronos y comitentes de la capilla mayor de la iglesia mercedaria creada en torno a la ermita ${ }^{1}$.

A partir de la década de los años treinta se desarrollará una febril actividad constructiva por toda la urbe, evidenciando un nuevo panorama artístico, más cercano al mundo del Renacimiento, rastreable no solo en los testimonios conservados sino a través de los documentos que han sobrevivido en distintos archivos. Durante dicho periodo la producción arquitectónica manifiesta una dualidad formal. Mientras el nuevo estilo se deja sentir en lo decorativo y superficial algunos elementos continúan siendo de tradición gótica. En los contratos de obra se observa una creciente adopción de programas renacientes y el manejo de algunos términos propios de un nuevo lenguaje. Fruto de este período renovador es la capilla mayor y la sacristía de la iglesia de la Merced, conjunto de singular importancia en el contexto de la Historia del Arte bastetano y andaluz.

\section{La capilla mayor}

Pasado el gran seísmo la familia Luna se ofreció a financiar la edificación de la capilla mayor a cambio del privilegio exclusivo de disfrutar del enterramiento para su estirpe en dicho lugar, siguiendo uno de los fenómenos que caracteriza la arquitectura tardogótica europea y en especial la española. Nos referimos a la construcción de una gran capilla mayor de carácter funerario sirviendo de panteón de relevantes personajes. Esta tipología tuvo una gran repercusión en la arquitectura española de la Edad Moderna y es una prueba más, junto a las bóvedas de crucería y otros elementos (arcosolios, leones, escudos de tipo alemán...), de la pervivencia del mundo gótico en pleno siglo $\mathrm{XVI}^{2}$.

Aunque en 1534 se firmaba un contrato para la edificación de la capilla mayor con el maestro Miguel desconocemos si el mencionado proyecto se llegó a ejecutar. La construcción definitiva se levantó en los años cuarenta por doña Constanza de Lugo, reflejando, una vez más, el importante papel de mecenazgo que realizaron algunas damas de la nobleza tras quedar viudas, convirtiéndose en promotoras de importantes obras de arte, siguiendo ejemplos tan relevantes como el de María de Luna ${ }^{3}$ en Baza o María Manrique, duquesa de Sessa, en los Jerónimos de Granada, la capital del reino ${ }^{4}$. Este tipo de mecenazgo se extendió por toda la península, pudiendo mencionar, entre otras, la destacada figura de Catalina Fernández de Córdoba y Enríquez en el Reino de Córdoba, nieta de la cuñada de nuestra comitente y María Enríquez de Luna, duquesa de Gandía, en el Reino de Valencia, sobrina de nuestra patrocinadora ${ }^{5}$.

El 28 de febrero de 1546 doña Constanza de Lugo, viuda desde hacía cinco años, firmaba la contrata con el cantero Martín de Alzaga bajo la traza de Rodrigo de Gibaja,

1. Lázaro, 2004: 67-98. Luis de Acuña era primo de María de Luna (hermanastra de Melchor de Luna), al ser las madres de ambos hermanas. Señalar un hecho relevante que pudo influir, de forma decisiva, en la elección de la capilla mayor de este convento como panteón familiar: que los padres de Constanza Pérez de Lugo disponían de un enterramiento en el primitivo templo mercedario, cerca de la capilla mayor. Desde aquí dar las gracias al obispado de Guadix por la autorización para realizar las fotografías y a don Emilio Fernández, párroco de San Juan y la Merced por su amabilidad y por abrirnos el templo para realizarlas. Agradecer igualmente el trabajo y el esmero de Agustín Orduña en las fotografías realizadas para este artículo.

2. Rodríguez, 2011: 81-110.

3. Lázaro, 2003: 203-259. La profesora Lázaro Damas pone de manifiesto en este artículo el destacado papel de mecenazgo de doña María de Luna, cuñada de Constanza Pérez de Lugo.

4. Collado, 2010: 169-184.

5. Olmedo, 2014: 27-46. 


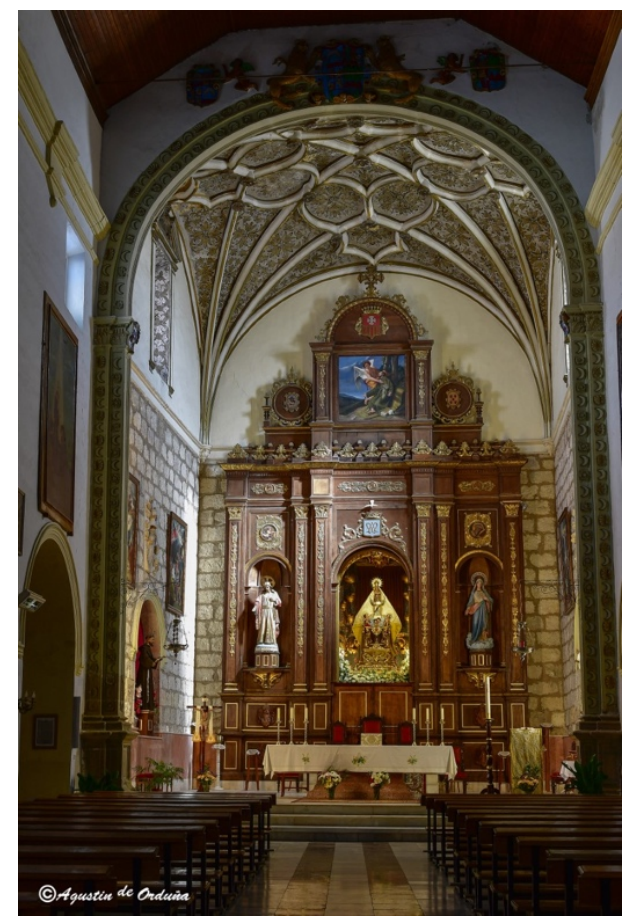

Fig.1. Vista general de la Capilla Mayor.

maestro que estaba dirigiendo las obras más relevantes de Baza y su Abadía (Magaña, 1978: 430). Según el profesor Rubio Lapaz estamos ante el máximo exponente de la actividad constructiva del quinientos en el altiplano granadino, artífice que estaba desplegando una intensa labor durante las décadas centrales de la centuria ${ }^{6}$. Cuando se levanta esta capilla Gibaja se encontraba en el cenit de su carrera artística, era quién llevaba la mayoría de las obras de cantería de las altiplanicies granadinas, siendo requerido igualmente por poblaciones de reinos limítrofes, trabajando en Quesada y en La Iruela (1537), poblaciones del Reino de Jaén y en Cehegín (1548), en el Reino de Murcia.

Martín de Alzaga introdujo ciertos cambios que implicaron pequeñas modificaciones del diseño primitivo, solicitando tras la finalización de la construcción (1549) que les fuesen pagadas. El peritaje de la obra añadida lo realizaron los maestros de cantería Juan de Acebo y Andrés de Vandelvira, presentes en la ciudad en ese momento.

En primer lugar aumentó, levemente, la superficie y la altura de la capilla ${ }^{7}$. En cuando a los cambios visibles más evidentes entre la traza aprobada y la ejecutada señalar el diseño de los contrafuertes cuadrados trazados por Gibaja y los de formato cilíndrico ejecutados por Alzaga. El resto de los cambios consistieron en pequeñas modificaciones centradas en el arco toral y en las molduras, y varios elementos decorativos, de los pilares dónde éste se apoyaba, tanto en los pedestales como en los capiteles ${ }^{8}$. Tras finalizar la tasación de la construcción los maestros aseguraban que el coste de los cambios efectuados, de las mejorías llevadas a cabo, ascendía a 144.799 maravedíes.

El diseño siguió, en líneas generales, el de la capilla de los Araoz de esta ciudad, obra trazada por Diego de Siloé: planta, arco toral, formato de los contrafuertes, similar disposición de los escudos y parecida bóveda ${ }^{9}$. En la elección de la traza pudo tener que ver tanto el artífice como la comitente, dado que doña Constanza era hermana de la esposa de

\footnotetext{
${ }^{6}$. Rubio, 1999: 155.

7.Archivo de Protocolos de Granada (APGr, Granada), Baza, Juan de las Navas, 1549, ff. 629r/630v. Igualmente aumentó (un pie) el grosor de la pared de la cabecera.

${ }^{8}$. Al incrementar la superficie construida (ensanchado y alargado) se produjo una pequeña alteración en el diseño original de la bóveda.

9. Segura/Valero, 2017: 341-355.
} 


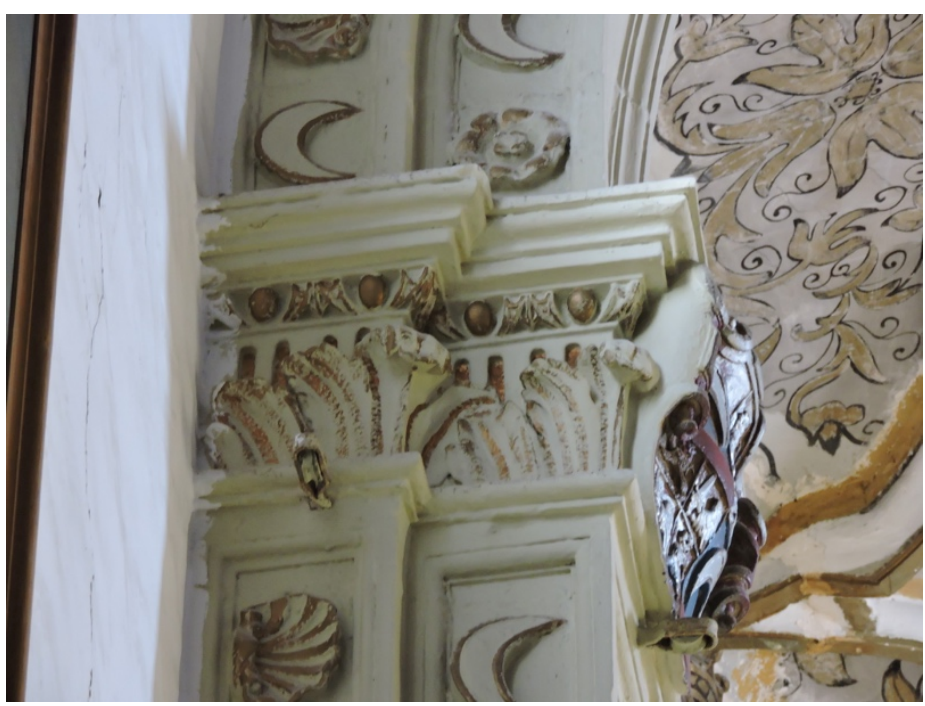

Fig.2. Capiteles.

Juan de Araoz. Aunque se siguen las líneas principales de la mencionada capilla hay algunos elementos puntuales que la acercan al crucero de la iglesia de San Jerónimo ${ }^{\text {to }}$, especialmente visibles en las pilastras y capiteles, más en la órbita de Alonso de Cobarruvias de los años treinta que en la de Siloé.

\section{Arco toral}

Como señalara el ilustre historiador Manuel Gómez Moreno, en su visita de 1891, la capilla presenta un arco toral semicircular ${ }^{11}$ apeado en pilares configurados por dobles pedestales escalonados sobre los que se apoyan esbeltas pilastras cajeadas de orden coríntio. A Gibaja le interesó, como ya les había interesado a otros tracistas, hacer valer la plástica rotunda de estos soportes, recurriendo a los órdenes clásicos para configurarlos.

Es en el cajeado de las pilastrillas dónde se desarrolla un programa decorativo e iconográfico con labores renacentistas en relieve recorriendo su trayecto, el del arco y el de la rosca sobre éste. Quedan adornados dichos elementos constructivos con medias lunas, alternando con rosetas en las pilastras principales y con veneras en las adosadas al paramento del templo. Aquí el tracista está intercalando elementos simbólicos en honor al linaje de los patrocinadores, la luna, con otros decorativos y alegóricos presentes en las capillas de los familiares de los patronos: las rosetas del crucero del convento de San Jerónimo, fundación de los Enríquez-Luna y las veneras (relacionadas con la resurrección) de la capilla de los Araoz-Lugo en la iglesia colegial.

La arquitectura de la cabecera de este templo es una clara continuación de una de las variantes implantadas en la ciudad tras el gran terremoto, empeñada en labores eminentemente decorativas, no sólo en el arco toral sino con los escudos que inundan el resto del paramento que hay sobre el mismo.

Sobre las pilastras capiteles de orden semicorintio, sin las habituales volutas, manteniendo gran similitud con los del crucero de San Jerónimo, corona de hojitas alrededor del vaso, estriado vertical, equino de ovas y dardos y un ábaco sin tallar como remate, elementos todos ellos de corte clásico. Creemos que su precedente más evidente está en una de las variantes del primer Renacimiento difundidas en España ${ }^{12}$.

10. Segura/Valero, 2017: 69.

11. Instituto Gómez Moreno (IGM, Granada), Legajo CXXVII, nº 2141.

12. La diferencia con los capiteles de San Jerónimo es que aquí hay un elemento más, el estriado por encima de las hojas de acanto. Estos capiteles recuerdan a uno de los modelos del tipo alcarreño, o mendocino, utilizado 


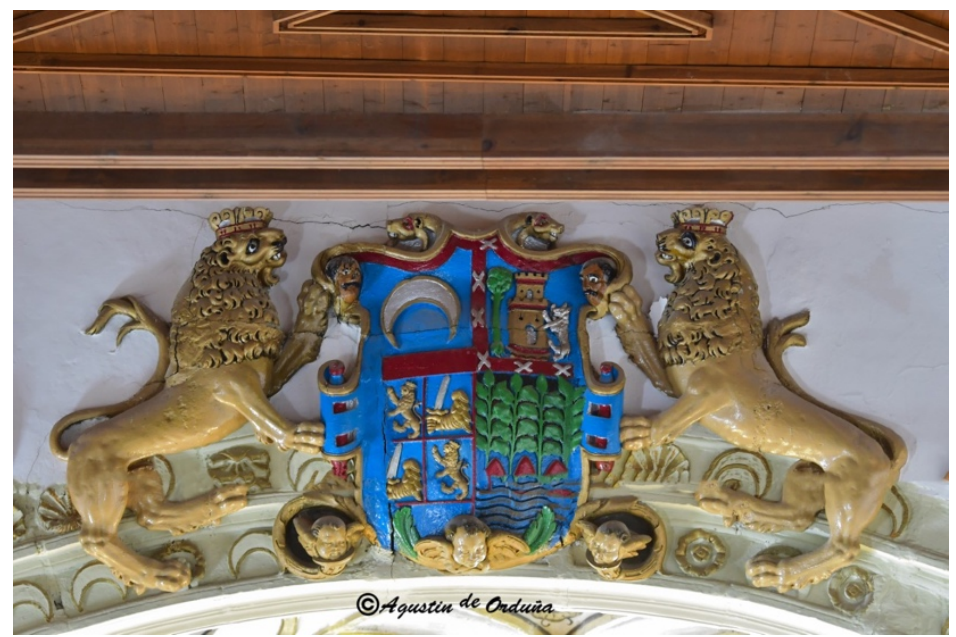

Fig.3. Escudo de los Luna-Pérez de Lugo.

Como señalara Manuel Gómez-Moreno sobre las caras internas de los capiteles los escuditos de los fundadores. La heráldica del matrimonio se volverá a repetir sobre el arco toral y sobre los arcosolios de sus enterramientos, exhibiéndose la del ilustre caballero a la izquierda y la de la dama a la derecha, siguiendo la estricta división que otorgaba el lado del Evangelio al hombre y el de la Epístola a la mujer. Desde finales de la Edad Media el escudo servía como elemento de identificación de una familia cuyo valor se demostraba en los campos de batalla, torneos y demás actividades guerreras. Los escudos que se exhiben en este periodo son de mayor tamaño y número. Con la llegada del Renacimiento se convierten en un elemento clásico del que se ocupan algunos teóricos como Serlo (libro IV), motivo que sirve para potenciar la idea renacentista de fama en el exterior e interior de construcciones civiles y religiosas, situándose en un lugar preeminente de las mismas.

Sobre la clave del arco el artífice despliega la espectacular heráldica del matrimonio fundador flanqueada por leones, disponiendo a ambos lados, y en un formato más pequeño, las de sus respectivas familias custodiadas por ángeles, dentro de una honda preocupación por la gloria de sus linajes, subrayando la pervivencia de los mismos más allá de la muerte.

Mención especial merece el escudo central, todo un paradigma de los cambios heráldicos que tienen lugar en este periodo. Esta notable pieza se convierte en la protagonista principal del arco y resume la trayectoria familiar, e histórica, de los Luna y los Pérez de Lugo. La unión de estas dos importantes estirpes hizo preciso una combinación de las armerías de las familias más relevantes con las que habían emparentado hasta el momento. Se resolvió recurriendo al invento castellano por excelencia: el cuartelado heráldico. El escudo está dividido en cuatro cuarteles, quedando en los de la izquierda los linajes relacionados con los Luna y en los de la derecha los vinculados a los Pérez de Lugo. Aunque no es muy frecuente algunos escudos en piedra, como los presentes, están policromados ${ }^{13}$. El estudio detallado de estas armas lo veremos más adelante, cuando analicemos los arcosolios.

Para magnificar su presencia, y consciente de su notable efecto plástico, el artífice nos lo muestra con leones a modo de tenantes, recurso decorativo muy habitual en la arquitectura tardogótica castellana que se propagó durante la Edad Moderna. En posición inclinada, la postura más agresiva del animal, con rostro amenazante, pareciendo transmitir protección del grandioso escudo y de las familias simbolizadas en el mismo.

por Lorenzo Vázquez en la planta baja del palacio de Antonio de Mendoza de Guadalajara, ocupando más espacio aquí las hojas y menos el estriado.

13. Fueron repintados de forma inadecuada, con pintura brillante. 


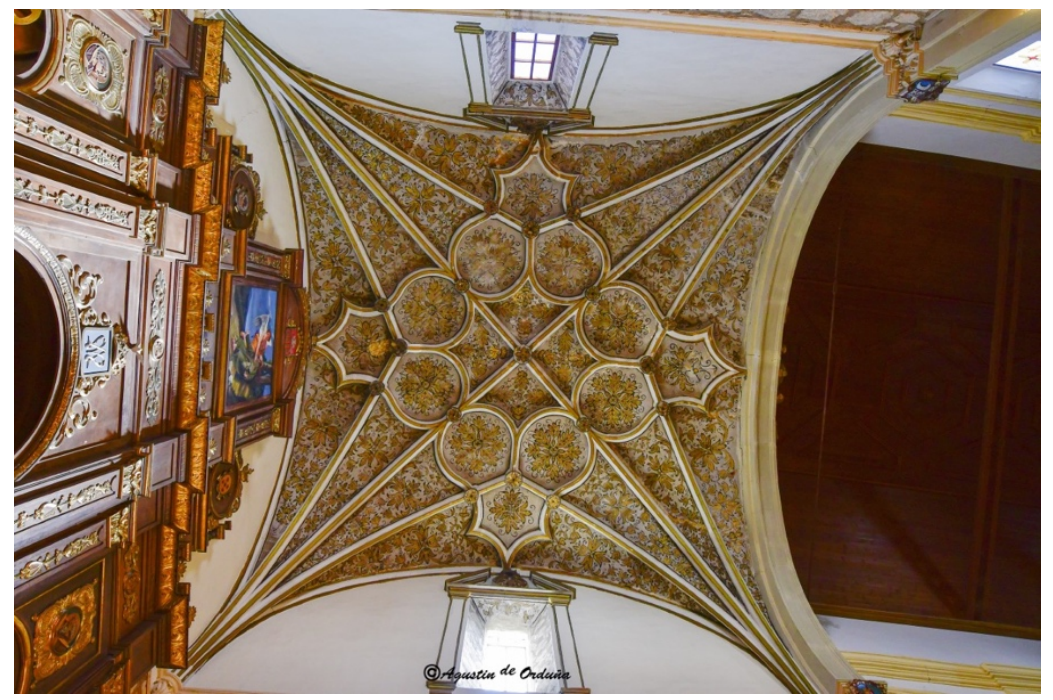

Fig.4. Bóveda estrellada de la Capilla Mayor.

Pese a la extrema riqueza de contenidos que puede expresarse a través de la imagen del león no puede negarse que muchas de las representaciones de este animal tuvieron como fin último un mero papel ornamental. Como animal decorativo y simbólico se ponía a los pies de los reyes de la corona de Aragón al final de la Edad Media, signo de realeza y fortaleza. El león está coronado, quizás con la intención de destacar la relevancia del linaje que está protegiendo, relacionado con varias casas reales peninsulares, especialmente con la de Aragón tras el matrimonio de María de Luna con Martín I en $1372^{14}$.

Los leones son frecuentes encontrarlos en edificios religiosos, representando, en muchos casos, a guardianes de las capillas. Simbolizan la defensa y protección frente a posibles agresiones externas. El cristianismo se apropió de ellos como símbolo de Cristo y de la resurrección, en virtud de su carácter vigilante y protector, utilizado en los sarcófagos romanos, tomando en el Renacimiento un nuevo impulso ${ }^{15}$.

Los escudos laterales, de menor tamaño, se presentan enmarcados por sendos ángeles de candoroso rostro, a modo de tenantes, habiendo sido eliminados los de los extremos en las intervenciones de los años ochenta del siglo XX. La figura del ángel es un recurso ornamental muy frecuente en la Antigüedad que volvió a recuperarse en los albores del Renacimiento, teniendo su antecedente más evidente en los situados sobre la portada de la capilla de los Araoz.

Los ángeles, suspendidos en el aire, se muestran en actitud de guardianes de la capilla y de las almas de los linajes allí enterrados, como si las acompañaran mientras llega el juicio fina $1^{16}$. En la tasación del coste final de la talla de los escudos se señalaba que el importe por realizar las figuras de los dos leones equivalía al de esculpir los cuatro ángeles ${ }^{17}$.

\section{Interior de la capilla}

14. En los siglos bajomedievales el león aparece coronado como rey.

15. Desde la Antigüedad vemos al león asociado a los conjuntos funerarios (Egipto, Asia Menor y Grecia) dónde tenía como significación esencial la guardia, pues se pensaba que este animal no dormía y de hacerlo era con los ojos abiertos, pasando a ser imagen de la vigilancia (Plinio y los Salmos CXXXI). Con el nacimiento de la heráldica en el siglo XII el león se convirtió en la figura preferida en los blasones medievales.

16. Según algunos tratadistas su uso suele ser prerrogativa especial de reyes y príncipes, no pudiendo usarlos ningún linaje si no disfrutaba de permiso especial, concesión o privilegio real. En ocasiones altas dignidades eclesiásticas lo utilizaron como signo de representación del dominio espiritual que residía en ellos.

17. APG, Ganada, Baza, Juan de las Navas, 549, f. 629. 


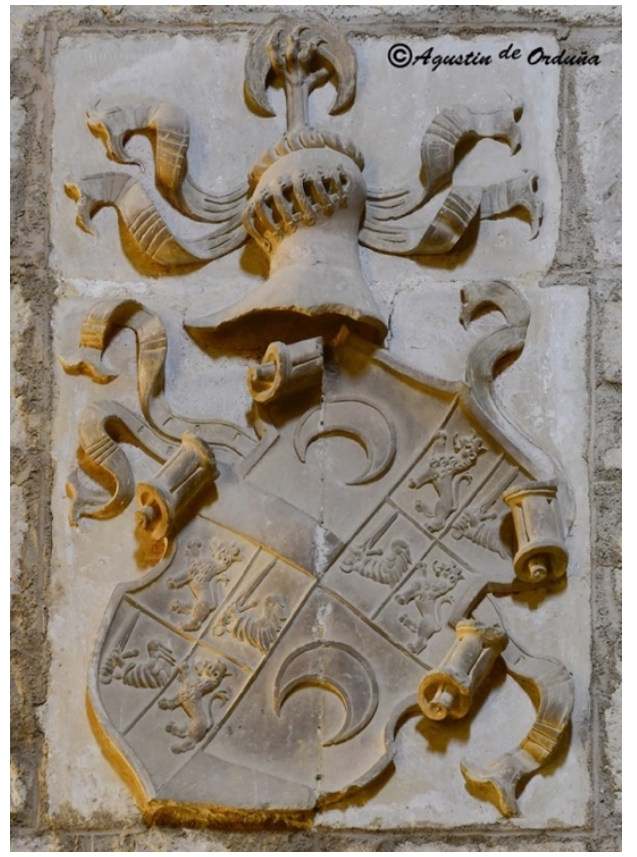

Fig.5. Escudo de Melchor de Luna.

El maestro hizo correr una imposta, a modo de entablamento liso, sobre los muros perimetrales de la cabecera, utilizada posiblemente como soporte para un discurso simbólico, cuyo texto conmemorativo desconocemos al estar actualmente tapado por una capa de pintura. En esta capilla se utiliza la solución más sencilla y recurrente para embeber los nervios de la bóveda en los muros, la de colocar ménsulas en las esquinas. Estas piezas (con carácter ornamental, aunque den otra apariencia) sobresalen del plano vertical y se presentan perfiladas con una banda de hojas de acanto.

En los centros de los paramentos este y oeste, a poca distancia de la línea de imposta, se disponen los únicos vanos de iluminación de la cabecera. Ventanas abocinadas, adinteladas y de formato rectangular enmarcadas por pilastras de orden dórico coronadas por un frontón partido (rematado por pirámides emboladas) en cuyo centro se exhibe un escudo mercedario, intervención arquitectónica sin documentar, quizás del siglo XVII. La c

Se cierra la capilla por una bóveda tardogótica estrellada siguiendo uno de los diseños habituales de este periodo en la ciudad, muy similar a la de las capillas de los Araoz y Juan de Baena y a la del segundo tramo de la nave principal de la iglesia colegial ${ }^{18}$. Los nervios están repartidos a razón de tres por ménsula, conformando una estrella de ocho puntas con diecisiete claves. Un abovedamiento de simbología cristiana (aludiendo a la bóveda celeste, al sacrificio de la misma, a la simbología del número 8, etc).

Durante la primera mitad del siglo XVI se seguían construyendo bóvedas de crucería estrellada por el peso de la tradición gótica y por imposición de los comitentes, la mayoría de las veces. Alonso de Covarrubias, Diego de Siloé, Rodrigo de Gibaja y la gran mayoría de los maestros de cantería de España, seguirán utilizándolas. La idea de Antigüedad Clásica se había extendido más en los elementos decorativos de los soportes que en las bóvedas. Gibaja las usó en todos los edificios de cantería en los que estuvo trabajando en Baza, tanto en los proyectos de otros arquitectos como en los trazados por el mismo.

En cuanto a la decoración pictórica de este espacio decir que se doró y policromó en el último tercio del siglo XVII. El 18 de enero de 1676 la orden solicitaba permiso para cortar madera y levantar un andamio con el objetivo de dorar la capilla mayor. Hoy en día se conserva dicho dorado en la bóveda, en el intradós y elementos que bordean las ventanas y en algún que otro componente decorativo más, casó de los perfiles de los relieves situados

18. Gómez, 1998: 210-211. 
en las pilastrillas y en el arco toral (lunas, rosetas, veneras, capiteles ${ }^{19}$. La intervención de la bóveda se centró en los nervios y en los plementos, decorados con hojarascas y motivos florales perfilados en color negro.

En relación al resto de policromía, la presente en los escudos situados en los capiteles, y sobre el arco toral, desconocemos si se efectuó en este periodo o en el siglo XVIII, aprovechando la renovación del patrimonio mueble de la capilla. El 3 de marzo de 1737 los mercedarios solicitaban permiso para cortar madera con el probable objetivo de construir el gran retablo barroco (1738-40) y un andamio para levantarlo ${ }^{20}$. El trabajo pictórico que debió realizarse en dicho intervalo de tiempo, quizás una actuación de restauración de la obra del XVII (y algo más), lo ejecutaron Jaime Mataiz, Diego Serrano y Miguel Jiménez (1730-1740), según se deduce de las inscripciones descubiertas sobre los nervios de la bóveda en $1973^{21}$, anotación conservada en el Archivo de Franciscanos de Murcia.

El presbiterio se pavimento con losetas de mármol blanco y negro a finales del siglo XVII. El 15 de octubre de 1680 la orden contrataba con el cantero Juan Tijeras, vecino de Macael, las losetas necesarias para pavimentar toda la iglesia. Se le pagarían 100 ducados para iniciar su elaboración, otros 100 cuando estuviese la mitad del trabajo ejecutado y el resto una vez finalizado ${ }^{22}$.

\section{Los arcosolios y su heráldica}

En el programa constructivo y decorativo de esta capilla están presentes varios elementos que formaron parte del primitivo proyecto al que no se le ha prestado atención por estar mutilados. Nos referimos a los arcosolios, arcos que, en forma de nichos incrustados en los muros, albergaron los sepulcros de los patrones, dispuestos de forma simétrica en los centros de los muros de levante y poniente. Esta elección en la tipología funeraria favorecía el adecuado desenvolvimiento de las ceremonias religiosas, sin obstaculizar la visión del altar mayor, magnificando a la vez las figuras de los fundadores con sus efigies, siguiendo un evidente interés en plasmar, de forma plástica y simbólica, los valores triunfantes de la memoria y fama de los patronos.

En su distribución se sigue la estricta división que otorgaba el lado del Evangelio al varón y el de la Epístola a la mujer. Se trata de dos nichos, hoy vacíos, que albergaron los sepulcros de los fundadores hasta la ocupación francesa. En la parte inferior debieron empotrarse las arcas, y las camas, con las esculturas yacentes de los comitentes. Hoy en día sólo quedan los arcos que configuraron estos enterramientos y los bellos escudos heráldicos sobre las claves de los mismos ${ }^{23}$.

El empleo de esta tipología apareció en la época imperial romana, siendo utilizada a lo largo de la Edad Media, y principios de la Edad Moderna, por numerosas casas nobiliarias. Quizás el linaje Luna-Pérez de Lugo esté siguiendo una solución usada, con anterioridad, por sus respectivas familias. Entre los ejemplos más destacados relacionados con sus antepasados señalar los arcosolios en los muros de la capilla del condestable don Álvaro de Luna en la catedral de Toledo, abuelo del comitente ${ }^{24}$.

Sobre los arcosolios se disponen las armas del matrimonio fundador, en clara alusión al orgullo de su linaje. Estas notables piezas heráldicas se muestran siguiendo la moda de los

19. Archivo Municipal de Baza (AMB, Baza), Actas del Cabildo, 18-01-1676. Se debería comprobar si hay dorados en el espacio comprendido entre la bóveda y la línea de imposta, superficies tapadas hasta los finales del siglo XX con papel pintado.

20. AMB, Baza, Actas del Cabildo, 03-03-1737.

21. Castillo, 2009: 157.

22. APG, Granada, Baza, Torres Sabiote, 1680, ff. 240-243.

23. Se debería comprobar si quedan algunas partes de estos sepulcros en los niveles bajos de los arcosolios, hoy cegados con material de obra.

24. Rodríguez, 2003:11-28. 
Fig.6. Escudo de Constanza Pérez de Lugo.

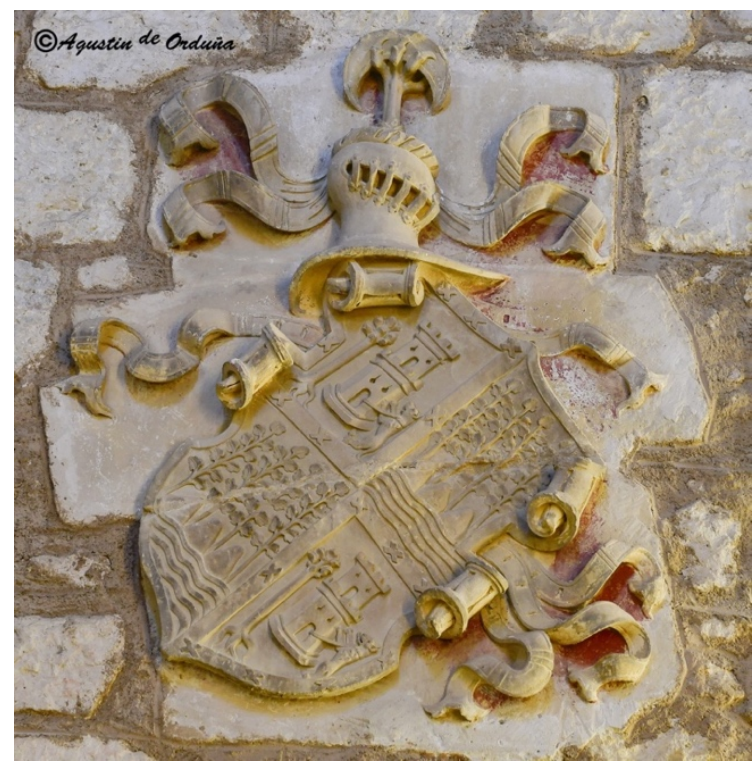

escudos de tipo alemán con el campo inclinado ${ }^{25}$. Apoyamos las reflexiones de la profesora Lázaro de que están realizados por un hábil escultor, quizás Lizana, destacando por la finura del relieve y por el dinamismo aportado en la disposición del cuero en sí (con los bordes enrollados) y por las cintas que ondean a un lado y a otro del yelmo ${ }^{26}$. Como remate cimeras con garra de águila sujetando media luna en lo alto, volviendo a remarcar el elemento identificativo y simbólico más evidente de este destacado linaje ${ }^{27}$.

La mayoría de los sepulcros más importantes de Baza debieron sufrir un grave expolio tras ser abiertos y mutilados durante la ocupación francesa, siendo en ese momento cuando se rompieron las cubiertas que sellaban las sepulturas de los ilustres personajes que allí descansaban en la obsesión por encontrar tesoros, con el agravante de que lo que no podían robar lo destrozaban ${ }^{28}$.

El hecho de que no se restauraran los arcosolios tras la huida del ejército napoleónico, y que en su lugar apareciesen pequeños altares apreciables en fotografías de principios del siglo XX, puede que tenga que ver con la circunstancia de que la última representante del linaje falleció poco después de la Guerra de Independencia sin descendencia, por lo que sus herederos, poco vinculados a esta ciudad, no tuvieron presentes los sepulcros y la recuperación de dichos espacios funerarios.

\section{Arcosolio de Melchor de Luna y la Puente}

El 6 de octubre de 1553 doña Constanza de Lugo contrataba con el cantero Sebastián de Lizana, vecino de Purchena (Almería) ${ }^{29}$, la ejecución de la tumba de su esposo, fallecido en 1541. Dicho maestro estaba despuntando en el panorama arquitectónico y escultórico del sudeste español, en los reinos de Murcia y Granada. Para algunos historiadores fue el principal discípulo de Florentín, trabajando a sus órdenes en las obras de la catedral de Murcia entre 1523 y 1529. Una vez fallecido su maestro se trasladó a Granada dónde paso a trabajar

25. Ambos escudos están partidos por la mitad lo que nos hace pensar que existe la posibilidad de que han sido reutilizado de otro lugar, quizás de los sepulcros de los patronos tras ser mutilados tras la ocupación francesa.

26. Lázaro, 2004: 78.

27. La luna en el escudo de doña Constanza debe estar relacionado con el hecho de que don Alonso Fernández de Lugo, destacado antecesor del linaje de la comitente, contrajo matrimonio con una integrante de esta ilustre familia, con Catalina Martínez de Luna.

28. Magaña, 1978: 100.

29. APGR, Baza, Juan de las Navas, 1553, ff. 446r/v. 
con Siloé y a colaborar, en alguna que otra ocasión, con Rodrigo de Gibaja, quién había monopolizado las obras de cantería en las comarcas de Baza y Huéscar ${ }^{30}$.

El sepulcro fue realizado en mármol blanco de Macael sin impurezas. La cama debía de medir nueve pies de largo, cuatro y medio de ancho y cinco cuartas de alto, contando con una grada alrededor y garras en las cuatro esquinas inferiores, conforme al diseño presentado. Sobre la cama la escultura yacente de don Melchor, de siete pies de largo, revestida con sus mejores galas, con armadura y con espada, en recuerdo de una de las facetas más características en su vida, la de guerrero, destacado militar castellano. El diseño del arnés debía ser fiel a la muestra que le entregaba la comitente.

Por debajo una inscripción que debió informar sobre la condición militar de este caballero, miembro del ejército de los Reyes Católicos, presente en la conquista de la ciudad de Baza. En la cabecera de la cama se había de esculpir el escudo de armas de dicho señor, ocupando todo el frente.

Doña Constanza pagaría por el trabajo 100 ducados, estando obligada a aportar todos los materiales para su ejecución. Los primeros 20 ducados se entregarían en 15 días a partir de la firma del contrato. El resto se aportaría a media que fuesen avanzando los trabajos. Lizana se comprometía a entregar la obra el 24 de junio de 1554. Si el maestro no cumplía el plazo establecido la comitente podría encargárselo a otro especialista, pagando el trabajo de éste el primer contratado.

Finalizada la construcción del sepulcro debía ser tasado por dos oficiales. Si resultase valer más de 100 ducados Lizana no podría exigir más de dicha cantidad, teniendo que conformarse con el dinero pactado. Suponemos que doña Constanza no quería que sucediese lo acaecido con la construcción de la capilla y los añadidos realizados por el contratista. En el caso de ser tasado por debajo de 100 ducados Lizana tendría que devolver el dinero cobrado de más. Nada hemos localizado en relación al sepulcro de doña Constanza, quién falleció en 1556.

Sobre el arcosolio del Evangelio el escudo cuartelado de don Melchor de Luna, el fundador. El blasón resume la historia familiar de dicho señor, las heráldicas de los linajes con los que habían entroncado sus antepasados más cercanos de origen noble ${ }^{31}$. El primer y tercer cuartel alude a los Luna, una de las ocho casas nobiliarias más importantes de Aragón: en campo de gules un creciente ranversado de plata y punta del mismo metal. La mayoría de los colores y/o metales descritos en este blasón, y en el siguiente, son genéricos, dado que ambas piezas ni tienen ni conservan policromía.

En el segundo y tercer cuartel las armas de la abuela del comitente, las de los Manuel: león rampante y brazo alado de oro con espada de plata. El abuelo de don Melchor mantuvo relaciones extramatrimoniales con una dama castellana, Margarita Manuel de Villena, con la que concibió varios hijos bastardos, siendo el primogénito, Pedro, padre de nuestro comitente, caballero al que legaría el señorío de Fuentidueña (Segovia).

Visto el escudo aportaremos unas pinceladas sobre la dinastía de los Luna, cuyo apellido proviene de la villa zaragozana del mismo nombre. La mayoría de los genealogistas, $\mathrm{y}$ heraldistas, recogen su aparición en tierras aragonesas a partir del siglo XI, afirmando que este linaje procede de don Bacalla, renombrado caballero de origen navarro que conquistó la villa de Luna (Zaragoza), cuyo señorío recibió, incorporando dicho nombre, y simbolismo, a su apellido y a su escudo de armas. Este ilustre caballero tuvo tres hijos con los que se iniciaron las tres ramas principales de esta dinastía, siendo la de los Martínez de Luna la de nuestro comitente, destacando en la historia de España dos de sus integrantes: el contestable Álvaro de Luna, su abuelo y el papa Luna, tío-abuelo de éste último. A pesar de la caída del linaje tras el ajustamiento del contestable en 1453, la corona, a propuesta de varios consejeros, restableció la memoria del valido, devolviendo a sus descendientes títulos y dignidades.

30. Entre las obras en las que estuvo trabajando destacar la portada de la iglesia de Santiago de Guadix, trazada por Siloé.

31. Desconocemos porque no están las armas del apellido Puente. Tal vez su madre no era de origen noble. 
Melchor de Luna fue el tercer hijo de don Pedro de Luna, I señor de Fuentidueña, concebido tras el enlace con su segunda esposa, doña María de la Puente. Antes de instalarse en nuestra urbe debió seguir desempeñando sus funciones como militar, dentro de la tradición castrense familiar que retomarán sus descendientes, sirviendo a la corona durante gran parte de la Edad Moderna. Entre los cargos desempeñados a nivel militar señalar el de la alcaldía de la alcazaba de Guadix, al menos desde 1515 a 1519. En 1521 participaba en el ejército español contra los franceses en Navarra.

Los historiadores Luis Magaña, y López de Haro, afirman, sin documentación que lo avale, que don Melchor se quedó a vivir en Baza tras recibir un número destacado de posesiones tras la Reconquista y por petición expresa de la todopoderosa María de Luna, su hermanastra, mujer de don Enrique Enríquez, tío y mayordomo de Fernando el Católico, el mayor terrateniente del Reino de Granada ${ }^{32}$. Lo que parece evidente es que el importante patrimonio heredado de su suegro, el comendador Diego Pérez de Santisteban y la instalación de las residencias de las hermanas de los dos integrantes del matrimonio Luna-Lugo en dicha urbe tuvieron un peso decisivo en el asentamiento definitivo de este linaje.

Según el profesor Francisco Tristán, especializado en la ciudad del siglo XVI, nuestro comitente no formó parte de la primera generación de repobladores y por tanto no recibió propiedades, no constando su carta de donación. Aparece en las actas del cabildo a partir de 1518, año en el que se realiza el reparto de los bienes de su suegro ${ }^{33}$, uno de los caballeros más ricos de la urbe. Ese mismo año inicia un conflicto jurídico con el ayuntamiento por desviar una acequia para abastecer a un molino suyo ${ }^{34}$.

Desde los años veinte se convirtió en uno de los regidores locales, cargo que desempeñaron sus descendientes, de forma intermitente, durante toda la Edad Moderna. Siguiendo lo que hacían otros grandes linajes los Luna fundaron un importante mayorazgo ${ }^{35}$ y se asentaron alrededor de tres siglos en Baza, hasta la extinción biológica de la dinastía a principios del siglo XIX.

Como otros integrantes de la oligarquía bastetana los Luna-Pérez de Lugo poseían esclavos, mano de obra barata y signo de prestigio y distinción. En 1516 solicitaban, ante la Chancillería de Granada, que le entregasen un esclavo negro llamado Domingo, de 22 años, que había huido y se encontraba en dicha ciudad ${ }^{36}$.

\section{Arcosolio de Constanza Pérez de Lugo}

Sobre el arcosolio de la Epístola el escudo cuartelado de doña Constanza Pérez de Lugo. El blasón resume la historia familiar de dicha dama, las heráldicas de los linajes con los que habían entroncado sus antepasados más cercanos. El primer y cuarto cuartel alude a los Pérez de Santisteban y Sandoval. Un árbol y una torre con perro atado a la puerta y bordura de ocho cruces de San Andrés ${ }^{37}$.

32. Magaña, 1978: 556 y López, 1622: 153.

33. Fue uno de los pocos señores que obtuvo dos cartas de vecindad en el Repartimiento, con propiedades rústicas y urbanas en Baza y otras villas de su partido.

34. Como afirma dicho historiador hay un vacío documental de 1507 a 1518, del que no sabemos nada. Información cedida por dicho profesor, hecho que agradecemos enormemente.

35. Además del mayorazgo fundado por Melchor de Luna la familia disfruto de otros mayorazgos o vinculaciones a lo largo de la Edad Moderna, los fundados por Martín de Alarcón, Pedro de la Plaza Bravo, Pedro Nuño de Mata, Mariana del Rosal y Diego y Marina de Rueda. Dichas fundaciones disponían de propiedades en Granada, Baza, Almodóvar del Pinar (Cuenca), Segovia y Madrid (población esta última reflejada sólo en uno de los documentos consultados).

36. Crespo, 2007: 1061

37. En este escudo no está presente la banda de sable que lo atraviesa de izquierda a derecha (posible emblema de los Sandoval) en el resto de las heráldicas de la capilla, hecho que puede denotar que esta pieza se labró después. En cuanto al animal representado tenemos algunas dudas, podría ser un león. 


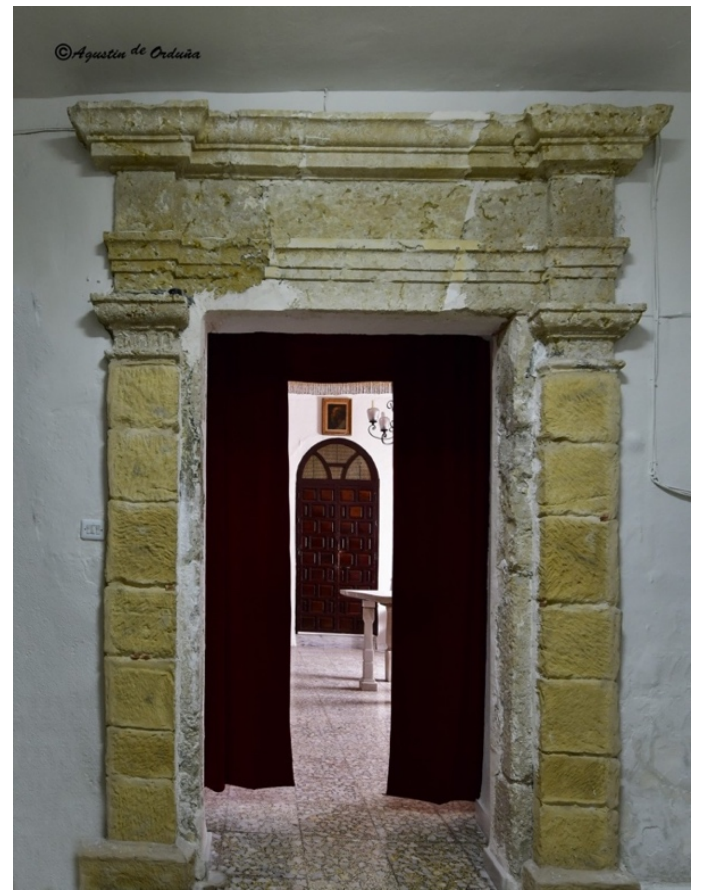

Fig. 7. Portada de la Sacristia.

En el segundo y tercer cuartel las armas de los Lugo, la familia materna de doña Constanza. Sobre ondas de agua tres peñas al natural, puestas en faja, una junto a la otra, sumadas de cuatro matas de ortigas con once hojas de sinople cada una ${ }^{38}$.

Nuestra comitente fue hija de Constanza de Lugo y del comendador Diego Pérez de Santisteban y Sandoval, señor originario de Letur (Albacete), caballero de la orden de Santiago, comendador del Campo de Montiel, teniente de mayordomo de los Reyes Católicos y su embajador en Francia (1502) y Navarra (1507). La hermana de esta señora era la esposa de Juan de Araoz, el hombre más rico de la ciudad tras Enrique Enríquez, cuñado de su marido. Su hermano fue Luis Pérez de Lugo, paje de Carlos V, regidor de Baza y veinticuatro de la ciudad de Granada a partir de 1513.

El historiador Luis Magaña localizó interesantes y comprometedores documentos relacionados con un hecho delicado en el que estuvo involucrada dicha dama y sus sobrinas Constanza y Luisa de Araoz, las cuales quedaron bajo su protección tras el fallecimiento de sus padres. Ambas doncellas, casadas en secreto con dos regidores, fueron llevadas por la fuerza a casa de su tía dónde fueron obligadas a declarar, con amenazas de muerte, que habían sido raptadas y que no habían contraído dichos matrimonios. Falleció dicha señora en $1555^{39}$.

De la relación marital de doña Constanza y Melchor de Luna hubo seis hijos, cuatro varones y dos féminas: Manuel, Álvaro, Pedro, Diego, María, que falleció siendo doncella y Ana, quién ingresó en las comendadoras de Santiago de Granada (Magaña, 1978: 555-562). La dinastía se asentó en nuestra ciudad alrededor tres siglos, disfrutando sus descendientes de enterramiento en esta capilla mayor desde la Reconquista hasta el primer tercio del siglo XIX, tras el fallecimiento de doña Joaquina de Luna, sin descendencia, la última representante de este ilustre linaje bastetano.

Desde un primer momento los Luna entroncaron con distintas casas de la nobleza española e italiana ${ }^{40}$, consiguiendo en el siglo XVI el señorío de la villa de Almodóvar del

38. El escultor aumento las matas de ortigas y las hojas de éstas a su libre albedrio. Tenía que haber presentado tres matas de ortigas con siete hojas cada una. Según el historiador Luis Magaña dicha señora era nieta del adelantado de Canarias.

39. Magaña, 1978: 253.

40. Manuel de Luna, el primogénito de Melchor, tras conseguir destacados cargos en Italia casó con doña Policena de Benzón, varonesa de Gallarán, quedándose a vivir en dicho país. 
Pinar (Cuenca) tras el enlace de don Álvaro, el primer heredero de este linaje bastetano, con Petronila de Alarcón y Pacheco. En el siglo XVIII señalar a Álvaro Pedro de Luna contrayendo nupcias con Francisca Zapata, hija del marqués de Bogarra. Será en el último tercio de la centuria cuando los Luna consigan el marquesado de Iniza tras el enlace de Joaquín de Luna y doña Francisca Chacón, VI marquesa de dicha casa nobiliaria. De este matrimonio nació Joaquina de Luna, VII representante del marquesado, quién tuvo un matrimonio, de idas y venidas, con el conde de Robledo. Entre 1805 y 1808 se separó de la residencia conyugal, siguiendo diversos pleitos contra su esposo. A partir de 1808, por consejo de la Real Chancillería, la pareja volverá a convivir los pocos años que le quedaron de vida a doña Joaquina. Al no tener hijos se extinguió la casa de Luna de la ciudad de Baza, heredando Teresa Carroz y Luna, monja y prima de la finada ${ }^{41}$.

\section{Exterior}

Exteriormente la capilla presenta un aspecto macizo y sobrio de cantería, destacando por la verticalidad de sus muros y por los potentes contrafuertes cilíndricos, siguiendo el diseño de la capilla de Juan de Araoz. Ascienden rectos, sin disminuir en grosor desde el suelo hasta acabar por debajo de la cornisa. Quedan coronados por candeleros (decoración añadida por el contratista) que tienen su antecedente más inmediato en la girola de la iglesia colegial.

Sobre el centro del paramento de poniente, para aportarle distinción al muro asomado a la vía pública, un repertorio de imágenes de notable fuerza plástica que han desaparecido en gran parte por el desmoronamiento de la piedra, plasmadas en el eje central, con el escudo de los Luna-Lugo y en los contrafuertes laterales, en los que apenas se perciben los restos de los escudos, de menor tamaño, de ambas familias.

\section{La sacristía}

El 15 de marzo de 1596 se firmaba el contrato para edificar la sacristía con Jusupe Díaz, maestro de albañilería y cantería que estaba destacando en el panorama arquitectónico local en las últimas décadas del siglo XVI. Este artífice había levantado diversas construcciones de carácter religioso en varios conventos de la ciudad: la capilla del canónigo Francisco de Madrid en Santa Isabel de los Ángeles (1587), la sacristía de San Jerónimo (1588) y la escalera (1592) y el refectorio de San Francisco (1593).

Nos encontramos ante una construcción de planta cuadrada de 22 pies, cuyos cimientos habían de tener una profundidad de 6 cuartas hasta llegar al firme. Se utilizó piedra de la cantera de la cuesta de Freila para levantar las esquinas (desde el suelo hasta la altura de la ventana) y las puertas, siendo los muros de tapiería enlucida. La bóveda, de ladrillo, había de construirse conforme a la traza presentada. El maestro aportaría la mano de obra y la mayoría de los materiales (piedra y arena) mientras el convento contribuiría con la madera necesaria y la teja para cubrir la sacristía.

El acceso principal a esta dependencia se hace bajo una portada de cantería de sencillo, sobrio y elegante trazado, compuesta por pilastras de orden semidórico (con capitel de estriado vertical) sobre las que descansa un entablamento formado por arquitrabe, friso liso y cornisa moldurada de escaso resalte, elementos que adquieren mayor desarrollo en los extremos, en el tramo situado sobre los capiteles ${ }^{42}$.

41. El conde de Robledo se quejaba de que su esposa se había separado de la vivienda conyugal desde finales 1805 y estaba causándole numerosos disgustos y pleitos por consejo de su padre y de un cura amigo de la familia. Tras la intervención de la Justica, a petición de su marido (asegurando que no existía ninguna sospecha de infidelidad ni maltrato), la Real Chancillería pedía que se intentase recuperar la convivencia marital con apoyo de un asesor.

42. Actualmente las pilastras están fajadas, obra posterior adosada y realizada con material artificial. En una fotografía de los años ochenta las pilastras se ven totalmente lisas y están enlucidas en yeso por el desmoronamiento que presentaban como consecuencia de la humedad. 


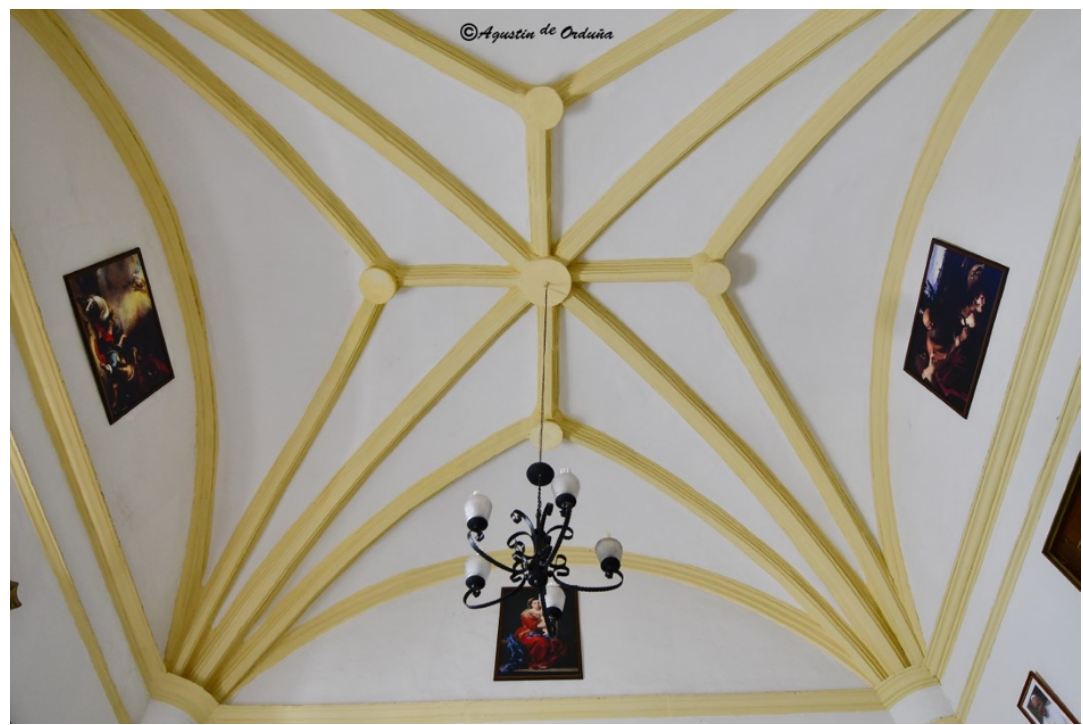

Fig. 8. Bóveda de la sacristía.

El plazo de ejecución de la obra sería de seis meses a partir de la firma de la contrata. Al comienzo de los trabajos se suministrarían 500 reales y cuando estuviesen avanzados los mismos, casi acabados, otros 100 o 200 . Una vez finalizada la construcción sería tasada por dos maestros propuestos por las partes implicadas, por el convento y por Jusepe Díaz. Dichos veedores realizarían una tasación del coste total de la obra, y presentada ésta, se le desembolsaría al constructor el dinero que faltase hasta cubrir el total del importe definitivo de la edificación.

Se cierra la capilla con una bóveda de crucería tardogótica cuyos nervios configuran una estrella regular de terceletes de cuatro puntas con cinco claves siguiendo el diseño utilizado en las capillas centrales de la girola de la iglesia colegial bastetana levantadas en las décadas de los años treinta y cuarenta. Su traza podría ser muy similar a la de la sacristía del convento de San Jerónimo (1588), construida por este maestro de cantería, obra desparecida.

$\mathrm{Al}$ igual que en la capilla mayor, bajo la bóveda está presente la línea de imposta y, en las esquinas, cuatro ménsulas en las que se apoyan los nervios. A diferencia de la anterior aquí la imposta ocupa más espacio y las ménsulas se presentan totalmente lisas, excepto los arranques de las mismas, perfilados por una banda de lengüetas, solución utilizada en las capillas centrales de la girola de la iglesia colegial.

\section{Conclusiones}

La construcción de la capilla mayor (1546) y de la sacristía (1596) del convento de la Meced sigue la solución más habitual en las edificaciones de cantería de la Baza del siglo XVI, una síntesis entre lo moderno y lo antiguo, una simbiosis entre la arquitectura renacentista y los últimos coletazos del gótico. Lo que se traduce en una solución arquitectónica caracterizada por el clasicismo en la utilización del arco de medio punto y los órdenes clásicos a través de las pilastras, recurriendo a las bóvedas tardogóticas como forma de cubrir estos espacios.

La tipología escogida, con decoración del nuevo estilo, debió encajar a la perfección con la nueva imagen que pretendía dar la orden de la Merced y la familia Luna, una arquitectura 
con pasado y con raíces pero renovada y esplendorosa, igual que su linaje, uno de los más importantes del altiplano granadino, enraizado directamente con la casa real de Aragón.

Como afirmara el historiador Rubio Lapaz estas edificaciones nos hablan de la importancia de la producción arquitectónica del quinientos en las altiplanicies granadinas y del destacado papel de Rodrigo de Gibaja, y otros canteros del siglo XVI, a nivel andaluz ${ }^{43}$.

43. Rubio, 1990:135. 


\section{Bibliografía}

Castillo, J.: Baza. Guías de Historia y Arte. Granada: Diputación. (2009).

Collado, M.J.: "La mujer granadina como mecenas de espacios funerarios durante el Antiguo Régimen”. En: Asparkía, (21), (2010), pp. 169-184.

Crespo, F. J.: El notariado en Baza a comienzos de la Edad Moderna. Estudio y catálogo de los protocolos notariales (1516-1519). Universidad de Granada (Tesis Doctoral). (2007).

Gómez, J.: El gótico español de la Edad Moderna. Bóvedas de crucería. Universidad de Valladolid. (1998).

Lázaro, M. S.: "Poder y mecenazgo nobiliario en Baza: Doña María de Luna". En: Péndulo, (4), Baza, (2003), pp. 203-259.

Lázaro, M. S.: "Consideraciones en torno a la historia constructiva del santuario de la Virgen de la Piedad de Baza". En: Péndulo, (5), Baza, (2004), pp. 67-98.

López, A.: Nobiliario genealógico de los reyes y títulos de España. Madrid: Luis Sánchez. (1622).

Magaña, L.: Baza histórica. Baza: Asociación Cultural de Baza y su comarca. (1978).

Olmedo, Y.V.: "Mecenazgo femenino en la arquitectura del antiguo Reino de Córdoba". En: Arenal, (21), (2014), pp. 27-46.

Segura, J. M. / Valero, C.: “La capilla de Juan de Araoz y Diego de Siloé”. En: Péndulo, (17), Baza, (2016), pp. 341-355.

Segura, J. M. / Valero, C.: "La capilla mayor y el crucero de la iglesia de San Jerónimo de Baza". En: Cuadernos de Arte de la Universidad de Granada, (48), Granada, (2016), pp. 51-71.

Rodríguez, R.M.: "Fartan sus iras en forma semblante: la tumba de Álvaro de Luna y el status de la imagen en la Castilla tardomedieval". En: Espacio, tiempo y forma, Serie VII, (16), (2003), pp.11-28.

Rodríguez, J.C.: "El tardogótico del sur: Andalucía y Canarias". En: La arquitectura tardogótica castellana entre Europa y América, (2011), pp.81-110.

Rubio, J.: “Análisis de la obra de Rodrigo de Gibaja, arquitecto del siglo XVI”. En: Cuadernos de Arte de la Universidad de Granada, (21), Granada, (1990), pp. 135-159. 